\title{
Assesment of the Effectiveness to Which Lecturers Apply Learner-Centered Techniques in Teaching and Learning Process in Universities in Tanzania: A Case Study of Mwenge Catholic University
}

\author{
Joseph Angelista ${ }^{1}$, Minja Gileard ${ }^{2}$ \\ Mwenge Catholic University, Box 1226 Moshi, Tanzania
}

\begin{abstract}
The study examines the effectiveness of implementing Learner Centered Techniques and approaches among lecturers at Mwenge Catholic University. Learner Centered Technique (LCT) is a competence-based instructional approach which seeks teachers' active involvement of students in the classroom processes with emphasis on students' learning. The study was guided by the following research questions; To what extent do lecturers and teacher students familiar with Learner Centered Teaching at MWECAU?

Which LCTs are most preferred by most lecturers during teaching and learning at MWECAU? What skills does the LCT promote in teaching and learning process? What measures can be put in place to improve the implementation of LCT at MWECAU? Both qualitative and quantitative designs were used to examine to what extent lecturers at MWECAU apply LCT targeting lecturers and students at MWECAU. Questionnaires were the main tool used to collect data and statistical package for social sciences (SPSS) version 20 was used to analyze quantitative data. Findings revealed that to a higher extent the lecturers in the university understudy use learner centered techniques in teaching and assessment. The findings also indicate that Learner Centered Techniques promotes students' creativity, critical thinking and independent learning. The Learner Centered Techniques used to encourage students' engagement and in problem-solving skills to apply in daily life.
\end{abstract}

Keywords: Learner centered, Teaching, Learning.

\section{Introduction}

In Tanzania Educational stakeholders such as curriculum planners and teachers conceive LCT in terms of the methods of instruction both participatory and non-participatory (URT, 2005). Participatory instructional methods include among others: group discussion, debates, role plays, demonstrations, study visits, case studies, film shows, games, simulation, projects, discovery learning and brainstorming. While non-participatory instructional methods included: question and answers, storytelling, songs, lecture, chalkboard notes and talks (URT, 1997). LCT is viewed differently whereby practitioners that learners' active engagement in a lesson does not guarantee students learning but teachers understanding of the approach and their pedagogical motivation to engage students in the instructional practice (Msonde, 2011; Mushi, 2004). Despite of the fact that LCT is viewed as a difficult endeavour for practitioners as it is felt that learner centered practices are not very familiar there is a need to assess the extent to which classroom teaching is learner-centered (Blumberg and Pontiggia, 2011).

Learner centered techniques have been suggested to be applied in primary, secondary schools and higher learning institutions for effective teaching and learning. Doherty and Hilberg (2007) pointed out that learner-centered pedagogy promoted student achievement. Cornelius-White, Jeffrey and Harbaugh (2009) explained that LCT is an instructional paradigm that requires learner's active involvement in the classroom practice. Learner's active classroom interaction according to Freire (1970) and Weimer (2002) is enhanced by the teachers' use of discovery, inquiry, and problem solving methods. Schiller (2009) argues that LCT approach denotes a shift in the instructional orientation and philosophy from teacher-centred to student-centred approaches. Tabulawa (1998) noted that, besides the popularity of LCT in the $21 \mathrm{st}$ century, in practice, classroom practices are predominantly teacher-centered rather than learner centered. Learners' active engagement in a lesson 
does not guarantee students learning but teachers understanding of the approach and their pedagogical motivation to engage students in the instructional practice (Msonde 2011, Mushi,2004). According to Keith, Rugambwa, Varvrus, and Maganga, (2016) their book on Learner centred approaches recommends that different use of LCTs in teaching and learning process tends to promote independent learning. This study therefore examine effectiveness of implementing learner centered techniques among lecturers in teaching and learning in higher institutions particularly Mwenge Catholic University.

\section{Research Questions}

1. To what extent do lecturers and teacher students familiar with Learner Centered Teaching at MWECAU?

2. Which LCTs are most preferred by most lecturers during teaching and learning at MWECAU?

3. What skills does the LCT promote in teaching and learning process?

4. What measures can be put in place to improve the implementation of LCT at MWECAU?

\section{Theoretical Framework (Problem-Posing Pedagogy)}

According to Freire (1970) theory of education mainly known as critical pedagogy in which proposes teaching approaches which empower learners with the freedom to construct knowledge where by critical perspective aims to enhance critical and emanicipatory thoughts in the learners. Freire opposes the teacher-centered approach referring to it banking model of education. According to Freire, the practice of banking model occurs when a teacher dominates classroom processes by mainly imparting knowledge of the subjects to students who are assumed to be tabularasa i.e. lacking prior knowledge and experience that they could share to make meaning of concepts under discussion. Freire called LCT approach as "Problem-Posing Pedagogy" where by students are actively engaged in the learning process. The pedagogy places the learner at the centre of the classroom practices by promoting the learner to explore and share his/her varied prior knowledge and experience consequently creating new understanding of the concepts (Freire, 1970).

Another theory is "Constructivist Theory" theory which asserts that learners receive knowledge through self-direction and connection with their environment (Kumar, 2006). Constructivist pedagogy training supports teacher competence and student success. Constructivist instructional methods encourage higher-order thinking, stimulating learning environments, and create multiple solutions for a single problem (Franklin, 2007). Bush (2006) and Kumar (2006) support the value of constructivist-based instruction because it connects students ${ }^{\text {ee }}$ world with learning pursuits in the classroom".

\section{Methodology}

In this study both qualitative and quantitative designs were used to examine the effectiveness to which lecturers at MWECAU apply LCT in teaching and learning process. The target population of the study included 33 lecturers and 586 students at MWECAU. Simple random sampling technique was used to obtain the respondents who participated in the study both lecturers and students. Questionnaires and structured interview guide were used to collect data in which they were both administered to lecturers and students. With regard to qualitative data, the notes based on interviews were noted in detail then data were condensed and presented using direct quotations from what participant said and then analyzed. Furthermore the quantitative data from each questionnaire and interview guide were categorized, coded and entered into a computer for computation of descriptive statistics. The Statistical Package for Social Sciences (SPSS) was used to run descriptive analysis to produce frequency distribution, percentages, means and standard deviation based on various characteristics of respondents.

\section{Presentation of the Findings and Discussion}

The students were asked to show the extent to which they are familiar with LCT and the following findings were obtained.

Table 1 Shows the Extent to which Students are Familiar with LCT

Describe the extent to which you are familiar with learner-centered pedagogy

\begin{tabular}{lll} 
& Frequency & Percent \\
\hline \hline Unfamiliar & 13 & 2.2 \\
Somewhat & 55 & 9.3 \\
neutral & & \\
Somewhat & 32 & 5.4 \\
un-familiar & 383 & 65.3 \\
Familiar & 103 & 17.5 \\
Very & 100 \\
familiar & 586 & 100 \\
\hline Total &
\end{tabular}


The findings in table 1 indicate that $65 \%$ of the students' participants were familiar with LCT while $17.5 \%$ were very familiar. About $14.7 \%$ responded that they were somehow or neutral while $2.2 \%$ were not familiar. Those who responded that they were not familiar were first year students who were considered being new and those who were not taking education programme where the LCT concept is taught as a course. The respondents who responded that they were very familiar considered to be either students from the education programme or where the lecturers apply the techniques during teaching. Generally the findings reflect that most of the students were aware and familiar with LCT. The findings concur with Blumberg and Pontiggia (2011) that when teachers and learners are aware of the teaching methods used they become more comfortable to engage into learning tasks. Therefore there is a need to have regular trainings for teachers in order to enhance teachers understanding and awareness on how to apply different LCTs in their teaching and assessment.

\section{How Lecturers Plan the Lessons}

About $37.2 \%$ of the respondents said that Lecturer decides on what and how to teach, $36 \%$ said Lecturers decides on lessons but uses student responses to drive lessons, and $23.8 \%$ said lecturers decided on lesson but uses student responses to shift teaching strategy while few 2.9 said lecturers used other methods. This finding reflects that the learners' roles in the teaching and learning process are being considered in lesson preparations and the actual teaching. There is relative involvement of learners either in making decisions about what and how to teach and the selection of teaching and learning experiences.

The level of involvement of students in matters related to teaching and learning process has a significant contribution to the effective instruction. However the findings show that some of the lecturers shift from the planned teaching strategies to fit the needs of the learners based on their nature and lecture hall facilities. The findings here are in support of Msonde (2011) which points out that whenever good plans and selection of teaching methods are made leads to enhanced students involvement at different stages of the lesson.

During the interview $85 \%$ of the lecturers involved said that the LCT techniques vary with the subject and the objective of teaching. From the findings therefore it reflects that proper planning and implementation of LCT influence the teaching and learning process as from what and how should the lesson facilitated. On the other hand one of the participants said that: We teach different subjects so we cannot use similar LCTs to teach science and art subjects altogether, science teachers have more opportunities to employ multiple techniques.

\section{Common Strategies used by Lecturers during Teaching and Learning}

The study sought to find out common and frequent teaching and learning techniques used by the university lecturers. Students responses show that $38.9 \%$ said that strategies used were lecturer directed Teaching and Learning 24.2\% said that they used group work, $88 \%$ said the discovery is used, and $21.9 \%$ presentation and minority $6.3 \%$ used question and answers. The findings indicated clearly that most of the respondents said that the discovery related teaching methods were applied by the lecturers during instruction as a dominant teaching strategy. On the other hand group work was regarded as somehow a common teaching method that the lecturers employ and this is because it is a multipurpose technique for both classroom instruction and assessment procedure. The significance of teaching through the identified method and strategies is that they promote inquiry, innovativeness, creativity and independent learning among the students. The methods also encourage the lectures to prepare their lesson activities that geared towards the achievement of the goals of the courses.

Table 2 Preferred Learner Centered Techniques used by Lecturers

\begin{tabular}{lllllll}
\hline & DS & SWD & N & SWL & L & M \\
\hline \hline $\begin{array}{l}\text { Discussion } \\
\text { N=546) }\end{array}$ & $6(1.1)$ & $8(1.5)$ & $27(4.9)$ & $102(18.7)$ & $403(73.8)$ & 4.63 \\
Role Play(N=534) & $23(4.3)$ & $22(4.1)$ & $92(17.2)$ & $175(32.8)$ & $222(41.6)$ & 4.03 \\
Ball Toss (N=521) & $46(8.8)$ & $30(5.8)$ & $128(24.6)$ & $153(29.4)$ & $164(31.5)$ & 3.69 \\
Jig Saw (N=520) & $36(6.9)$ & $37(7.1)$ & $117(22.5)$ & $152(29.2)$ & $178(34.2)$ & 3.77 \\
Anagrams (N=516) & $38(6.8)$ & $42(8.1)$ & $149(28.9)$ & $166(32.2)$ & $124(24.0)$ & 3.59
\end{tabular}




$\begin{array}{lllllll}\text { Bicycle } & 41(8.0) & 53(10.3) & 125(24.4) & 145(28.3) & 149(29) & 3.6 \\ \begin{array}{l}\text { Chain }(\mathrm{N}=513) \\ \text { Interactive(N=535) }\end{array} & 9(1.7) & 5(0.9) & 48(9.0) & 86(16.1) & 387(72.3) & 4.56\end{array}$

\section{Key:DS-Dislike it, SWD-Somewhat dislike it, N-Neutral, SWL-Somewhat like it, Like it, M-mean}

Majority $73.8 \%$ percent of the respondent prefers discublambaugh (2009) on learner centered instruction it is used by lecturers while 72.3 prefer interactive lecturthas ithis selection of a particular teaching method used by lecturers while the rest of techniques were repressemteds on the nature of the learners and the by a relatively large number of respondents.

However, the respondents also said that LCTs are used as methods of assessment. During the interview $53.1 \%$ of respondents said that lecturers used questions and answers for assessment, $18.1 \%$ said paper and pencil, $16.6 \%$ oral questions while minority 8.1 said class observation. The findings reflect that the LCT is not only in teaching but also as assessment procedures whenever possible. The findings agree with Cornelius-White, Jeffrey, \& availability of the required facilities and resources. One of the lecturers said this during the interview: When I employ group assignment it simplify my work in assessment because I mark few papers

Thus researchers in this study emphasize that some teaching and learning methods and techniques are selected based on the class size, competence, objectives of the lesson, the content and learning experiences target to be developed.

Role of LCT in Promoting the Learning Skills Table 3.Extent to which learner centered strategies promote skills

\begin{tabular}{|c|c|c|c|c|c|c|}
\hline & DS & SWD & $\mathrm{N}$ & SWA & $\mathrm{A}$ & M \\
\hline Critical Thinking $(\mathrm{N}=550)$ & $12(2.2)$ & $8(1.5)$ & $54(9.8)$ & $94(17.1)$ & $382(69.5)$ & 4.5 \\
\hline Independent Inquiry $(\mathrm{N}=531)$ & $\begin{array}{l}16 \\
(3.0)\end{array}$ & $10(1.9)$ & $85(16.0)$ & $180(33.9)$ & $240(45.2)$ & 4.16 \\
\hline Problem Solving $(\mathrm{N}=537)$ & $3(0.6)$ & $14(2.6)$ & $69(12.8)$ & $15(27.9)$ & $301(56.1)$ & 4.36 \\
\hline $\begin{array}{l}\text { Active } \\
\text { Participation(N=541) }\end{array}$ & $6(1.6)$ & $8(1.6)$ & $40(7.4)$ & $116(21.4)$ & $371(68.6)$ & 4.55 \\
\hline Creativity $(\mathrm{N}=535)$ & $6(1.1)$ & $11(2.1)$ & $54(10.1)$ & $120(22.4)$ & $344(64.3)$ & 4.47 \\
\hline Observation $(\mathrm{N}=544)$ & $\begin{array}{l}11 \\
(2.0)\end{array}$ & $20(3.7)$ & $46(8.5)$ & $176(32.4)$ & $291(53.5)$ & 4.32 \\
\hline
\end{tabular}

\section{Key: DS-Disagree, SWD-Somewhat disagree, N-Neutral, A-Agree, SWA-Somewhat Agree, M-Mean.}

The findings in the table 3 above show that $69.5 \%$ of the respondents agreed that critical thinking promote skills, 68.6 active group participation, $64.3 \%$ creativity, $56.1 \%$ problem solving, $53.5 \%$ observations, and $45.2 \%$ independent inquiry. The results from the study indicate that the use of LCT promotes the necessary skills required to make the learner a useful person in his or her life. The promotion of the very important skills is a reflection of what the learners expected to be in their future as professionals such as in teaching and others. Generally the problem solving expected to help the learners to deal with difficult situations in their daily life while observation skills help the learners to be inquisitive to their environment. The results are in agreement with Vavrus, Thomas, and Bartlett (2011) who found that the use of LCT in teaching and learning process promote skills related to inquiry such as problem solving, discovery, observation and innovations by the individual learners which in turn lead to creativity and critical thinking. During the interview one lecturer participant said that: 
When I apply LCT in teaching in my lesson the students become active and ask many questions than when I use lecture method because they are more involved in the lesson.

The findings from this light reveal that there is a need for the universities to support its lecturers with adequate skills and pedagogical experiences in order to improve their competence in applying learner centered techniques in their own teaching.

\section{Suggestion for Improving Teaching and Learning at MWECAU}

The following were the suggestions to improve teaching and learning at MWECAU

The respondents pointed out that the university should improve the provision of teaching and learning materials and resources for to lectures to facilitate teaching and learning through Learner Centered Techniques. During the interview one of the lecturer participated in the study said that:

I find it difficult to apply various teaching methods in my lessons because they are demanding and take time to prepare and organize the teaching learning materials before teaching and some time some materials and not adequately provided to fit the large classes.

About $85 \%$ of the lecturers participated in the interview suggested that there should be a balance in the number of students per class to make it manageable to enhance the use of LCT during their teaching. Another lecturer said this:

My classes are big I cannot afford to apply many LCTs during my lessons but I assign students in groups to share ideas about the lesson content and they can only brainstorm and share in pairs.

The results of the study shows that $67 \%$ of the university lecturers participated in the study proposed that the university should organize regular trainings and workshops for its Lecturers on Learner centered strategies for other departments apart from education. This would improve the use of LCT in teaching and learning in the subjects which are from non education program because the lectures do not have the basic knowledge in teaching or have little pedagogical skills especially related to LCT. The findings are in line with a study by Vavrus, Thomas, and Bartlett (2011) who also recommended for the faculty regular pedagogical trainings through in-service teacher education. On the same one of the lecturers in non education program said:

I have already attended two methodology workshops organized by the university but I am not yet confident in using all the teaching techniques I learnt in the training, I need more seminars to enhance my understanding.

The findings also found that $25 \%$ of the study respondents suggested that the use of information and communication technology to deliver lessons would enhance the use LCT in teaching and learning process. i.e computer

The lectures suggested that there should be trainings on how to teach and handle large class should be provided to help them to integrate LCT in the teaching and learning. The students $78 \%$ proposed that the lectures should learn and understand how the LCTs are applied before they enter the lessons and try the new methods for them to get opportunity of exploiting the weakness and strength of each technique.

\section{Conclusions}

To some extent implementation of LCT is effective at MWECAU which is a call for other universities in the country to apply for promoting learning in higher education. Majority of student teachers and lecturers understood well LCT and their implication in teaching and learning. They have been applying them for many years majority over five years and therefore is not a new phenomena.

During the implementation of LCT lectures acts as a facilitator, moderator and coacher however during implementation majority perceive their students to have average learning ability. Students are involved when lecturers plan for their lessons and during teaching and learning questions were a major assessment tool. Interactive lecture and debate are mostly preferred by teachers while students proffered discussion, group work and interactive lecture. Class size and room size were some of the factors affecting implementation of LCT however, student's numbers, the resources availability were also mentioned. The findings showed that LCT promotes problem solving and critical thinking skills.

\section{References}

[1] Blumberg, P. and Pontiggia, L. (2011). 'Benchmarking the Degree of Implementation

a. of Learner-centred Approaches'. Innovative Higher Education, 36 (3), 189 - 202.

[2] Bush, G. (2006, December). Learning about learning: From theories to trends. Teacher

a. Librarian, 34(2), 14-19.

[3] Cornelius-White, Jeffrey, H., \& Harbaugh, A. P. (2009). Learner-Centred Instruction:

a. Building Relationships for Student Success. Thousand Oaks, CA: Sage. 
[4] Doherty, R. W., \& Hilberg, R. S. (2007, September/October). Standards for effective

a. pedagogy, classroom organization, English proficiency, and student achievement. The Journal of Educational Research, 101(1), 24- 34

[5] Franklin, C. (2007). Factors that influence elementary teachers use of computers. Journal

a. of Technology and Teacher Education, 15(2), 267-294.

[6] Msonde, C. E. (August, 2011). Enhancing teachers' competencies on learner-centred

a. approaches through learning study in Tanzanian schools. (PhD Thesis), the

$b$. University of Hong Kong, Hong Kong.

[7] Mushi, P.A.K. (2004). From didactic to facilitative approach: Establishing conditions for

a. effective teaching and learning in higher education. Dar es Salaam: Dar es Salaam

b. University Press.

[8] Freire, P. (1970). Pedagogy of the oppressed. New York: Herder and Herder.

[9] Gibbs, G. (1995). Assessing student-centred courses. Oxford: Oxford Centre for Staff

a. Learning and Development.

[10] Keith, I, Rugambwa, A; Varvrus, F; Maganga, A. (2016). The handbook on learnercentred teaching: 78 Strategies to engage dents and motivate students to succeed in Tanzanian Schools. Project Zawadi.

[11] Schiller, S. (2009). Practicing LearnerCentred Teaching: Pedagogical Design and

a. Assessment of a Second Life Project. Journal of Information Systems Education,

b. 20(3), 369-381

[12] Tabulawa, R. (1998). 'Teachers' perspectives on classroom practice in Botswana:

a. Implications for pedagogical change'. International Journal of Qualitative studies

b. in Education, 11(2), 249-268

[13] Weimer, M. (2002). Learner-centred teaching: Five key changes to practice. San Francisco,

a. CA: Jossey-Bass.

[14] United Republic of Tanzania. (2005). Curriculum and teaching: Syllabus

a. for diploma teacher education. Dar es Salaam: MOEC.

[15] United Republic of Tanzania. (1997). Curriculum and teaching: Syllabus

a. for diploma teacher education. Dar es Salaam: MOEC.
[16] Vavrus, F., Thomas, M. and Bartlett, L. (2011). 'Ensuring quality by attending to

a. inquiry: Learner-centred pedagogy in subSaharan Africa'. Addis Ababa. UNESCO:

$b$. International Institute for Capacity Building in Africa. 